\title{
RETROSPECTIVE STUDY OF SEASONAL TRENDS OF MALARIA REPORTED CASES IN KANO STATE, NIGERIA
}

\author{
Yakudima, I. I. ${ }^{1}$ and Adamu, Y. M. ${ }^{2}$ \\ ${ }^{1}$ Department of Geography, Kano University of Science and Technology, Wudil, Kano State \\ ${ }^{2}$ Department of Geography, Bayero University, Kano State \\ *Correspondence author: isyakudima70@gmail.com (08065849089)
}

\begin{abstract}
Malaria is one of the leading causes of morbidity and mortality in Nigeria. Incidence of the disease varies over the space and time. This study investigates the seasonal trend of malaria incidence in Kano State. Data for four years (January 2010 to December 2013) was extracted from the routine consultation and recorded case sheets. A 12x4x2 three-way Analysis of Variance (3-way ANOVA) between subject effects factor design was performed on the raw data to explore the significance mean differences of malaria over time. Result revealed that there were 3,062,812 confirmed malaria cases reported during the period under study. The highest recorded cases were in the year 2011 with 858,061 cases or $28.02 \%$. Mean monthly cases showed that incidence concentrate during the rainy season between May and October with the peak month being September of the years under investigation. For forms of malaria, uncomplicated cases accounts $90.7 \%$ and severe malaria constitutes the remaining 9.3\%. Further, results from Analysis of Variance (3-way ANOVA) showed strong statistical main effect for months $(F=3.27, P=0.0001)$; strong statistical significant main effect for years under study $(F=1.03, P=0.0001)$ and strong statistical significant main effect for forms of malaria ( $F=8.80, P=0.0001$ ). In addition, the interaction effect between the three independent variables (Months, Years and Form of Malaria) was found to be significant $(F=2.19, P=0.0001)$. This interaction was followed up by conducting multiple comparison tests using Bonferroni correction. Results confirmed that the mean differences of months and years were statistically significantly difference. The study indicates that malaria is a common illness occurring all year round and therefore recommends for urgent intervention strategies to arrest the burden of the disease.
\end{abstract}

Keywords; Burden, Morbidity, Mortality, Severe Malaria, Uncomplicated Malaria

\section{INTRODUCTION}

Malaria is one of the major public health problems attracting global attention. The disease is associated with very high morbidity and mortality rate especially in sub-Saharan Africa countries (WHO, 2011). Malaria is endemic in 107 countries and 3.2 billion people are at risk of being contracted with the disease. It has been estimated that between 300-500 millions new clinical cases of malaria occur worldwide annually, leading to 1.5 to 2.7 million deaths, the vast majority being in Africa (WHO, 2002). Estimates of the global burden of malaria revealed that there were 189 million clinical cases world-wide in 2013 with 584,000 deaths (World Malaria Report, 2014). It was also reported that WHO African region suffered most with an estimated $90 \%$ of all the deaths recorded. Children under the age of five years accounts for the high proportion $(78 \%)$ of all deaths.

Nigeria is one of the countries where the disease became endemic and therefore experiencing very high number of malaria casualties. It was estimated that $30 \%$ of the population lives in areas of high to very high transmission zone, $67 \%$ lives in a moderate transmission area and 3\% in region of low to very low transmission (Roll Back Malaria, 2012). It was also estimated that about half of adults in Nigeria have attack at least once in a year, while children under five years have $2-4$ episodes of malaria annually (Katsayal and Obamiro, 2007). Despite so many gains in malaria prevention and treatment there is a widespread prevalence of malaria infection in the country. In 1999 for example, malaria hospital admission in the country accounts for $20 \%$ while outpatient attendance was 30\% (Lamikanra, 1999). More recently, the proportion of outpatient visit to Nigerian hospital due to malaria increased to $60 \%$ (Yahya et al., 2014, Ayanlade et al., 2013). Beyond morbidity and mortality, malaria presents enormous economic burden in the country. An estimated 132 billion Naira is lost annually in the form of treatment cost, prevention cost and loss of income due to failure to work during illness (FMOH, 2009).

Kano is one of the most populace states in Nigeria, and has multiple malaria-risk factors such as presence of numerous Dams/reservoirs, large and small scale irrigation schemes, dumpsites, favourable climatic condition and other triggering factors for transmission. Malaria remains one of the most important public health problems in the state.

Kano state is located in the eastern margin of the North-west Geo-political zone of Nigeria consisting of 44 local government areas. The state lies approximately between longitudes $7^{0} 42^{\prime} 12^{\prime \prime} \mathrm{E}$ to $9^{0} 22^{\prime} 22^{\prime \prime} \mathrm{E}$ and between latitudes $10^{0} 32^{\prime} 34^{\prime \prime} \mathrm{N}$ to $12^{0} 37^{\prime} 7^{\prime \prime} \mathrm{N}$. It is bounded on the west by the Katsina state and Kaduna state by the South-west. It shares a boundary with Jigawa state from the North and East. It is bordered in the South by Kaduna and Bauchi states. It covers a total land area of about $20,760 \mathrm{~km}^{2}$ (Figure 1). 


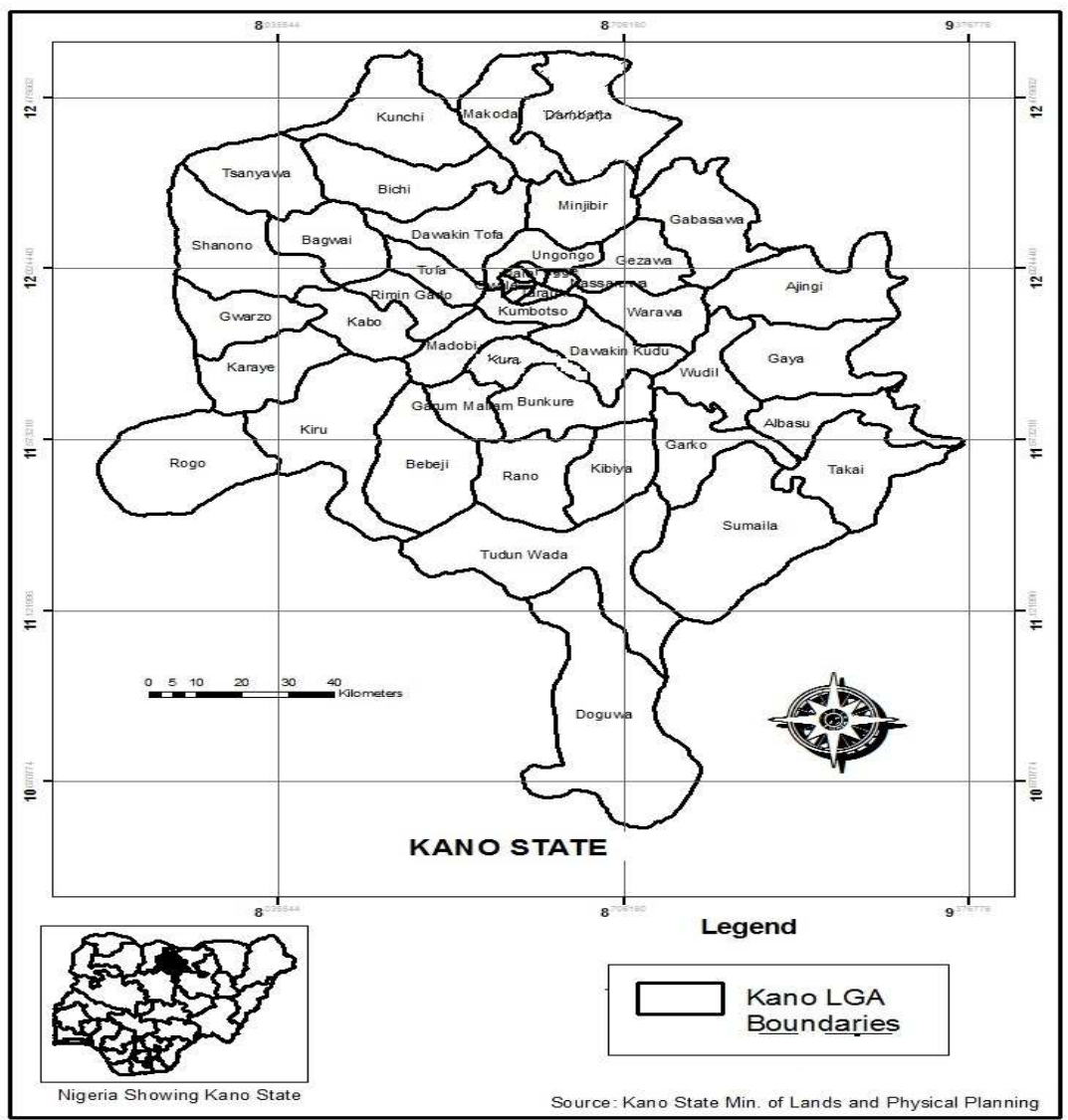

\section{Figure 1: The Study Area}

The state has a tropical wet and dry type of climate coded as Aw in the Koppen classification system. The annual mean rainfall in the state is between $800-$ $900 \mathrm{~mm}$. the annual amount could be between 1000 and $1100 \mathrm{~mm}$ in the extreme South and 500 to 600 $\mathrm{mm}$ towards the Northern margin (Olofin, 2008). The mean annual temperature is about $26^{\circ} \mathrm{C}$, but the mean monthly values ranges between $21^{\circ} \mathrm{C}$ and $23^{\circ} \mathrm{C}$ in the coolest months (November to February) and over $30^{\circ} \mathrm{C}$ in the hottest months of April/May (Olofin, 1987).

The natural vegetation of the state is a mixture of Sahel, Sudan and Guinea Savannah. Guinea Savannah dominated Southern Fringes and Sudan covers the larger part of the state (Olofin, 2008). Grasses are the main species of vegetation that dominated both cultivable and uncultivable lands and they hardly exceed 1.5m (Mustapha et al., 2014).

The 2006 Housing and Population Census put the population of the state at 9,383,682 (FGN, 2007) with an average density of about 447 persons $/ \mathrm{km}^{2}$. Hausa Fulani predominantly peopled the area.

\section{Study Methods}

The data used for this study was obtained from the office of National Malaria Control Programme, Kano State. The data consists of all reported malaria cases which were confirmed by microscopy or Rapid
Diagnostic Test (RDT) kits in various health centres from the 44 local governments of the state. The cases were reported and compiled at the state National office of malaria control programme in monthly surveillance form. The monthly malaria cases for the period of four years (January, 2010 to December, 2013) were extracted. The data includes all the monthly reported data of confirmed malaria cases on the following category:

a) Under 5 years uncomplicated malaria

b) above 5 years uncomplicated malaria

c) under 5 years severe malaria

d) above 5 years severe malaria

However, it is important to note that cases of malaria among pregnant women were not included in the study.

\section{Methods of data analysis}

Both descriptive and inferential statistics were used to explain the data. Mean monthly and mean annual incidences were plotted to observe the seasonal fluctuations. To identify seasonal variations of clinical malaria cases, three-way between subject's factorial analysis of variance (3-way ANOVA) or factorial design ANOVA was selected. Before the actual analysis, exploratory data analyses were conducted on the raw data to check that the assumption of homogeneity of variance has not been violated. 
A $12 \times 4 \times 2$ three way analysis of variance (3-way ANOVA) between subject effect factor designs was performed on the raw data to explore the significance mean differences of malaria over time. However, multiple comparison tests were performed to further explore the specific relationships among months and years groups. Statistical analyses were performed using SPSS version 21.

\section{Scope and Limitations}

This study had a number of limitations. First, the study did not measure malaria transmission intensity, despite the fact that the disease is highly endemic in the area. Secondly, the study used only four year data, (2010-2013) and this may not necessarily depict a clear picture on the temporal trend of the disease. However, this became necessary as it is only in these years that a comprehensive and reliable clinical data on malaria are documented. Thirdly, self-treated cases data and many other cases treated in private health centres were not available for this study. As a consequence, the study may not cover the whole dimension of malaria incidence at population level. Despite these challenges, the study revealed important information about malaria situation in the state.

\section{RESULTS}

Monthly Reported Malaria Incidence

Malaria cases were reported almost every month and season throughout the study period. A fluctuating trend was observed in the distribution pattern of malaria incidence in the observed months. The trend shows no clear picture about the pattern of the disease. The month with lowest incidence was December in 2011 and 2013 years while years 2010 and 2012 have their lowest incidences in the month of May and January respectively. Highest incidence was recorded in September for the 2010 and 2013 years while 2011 and 2012 have their maximum cases in January and August respectively (Figure 2). However, the overall mean shows that September has the highest number of cases while August and October showed a slight decrease in the prevalence as compared to September. The months of December and January have the lowest records (Figure 3).

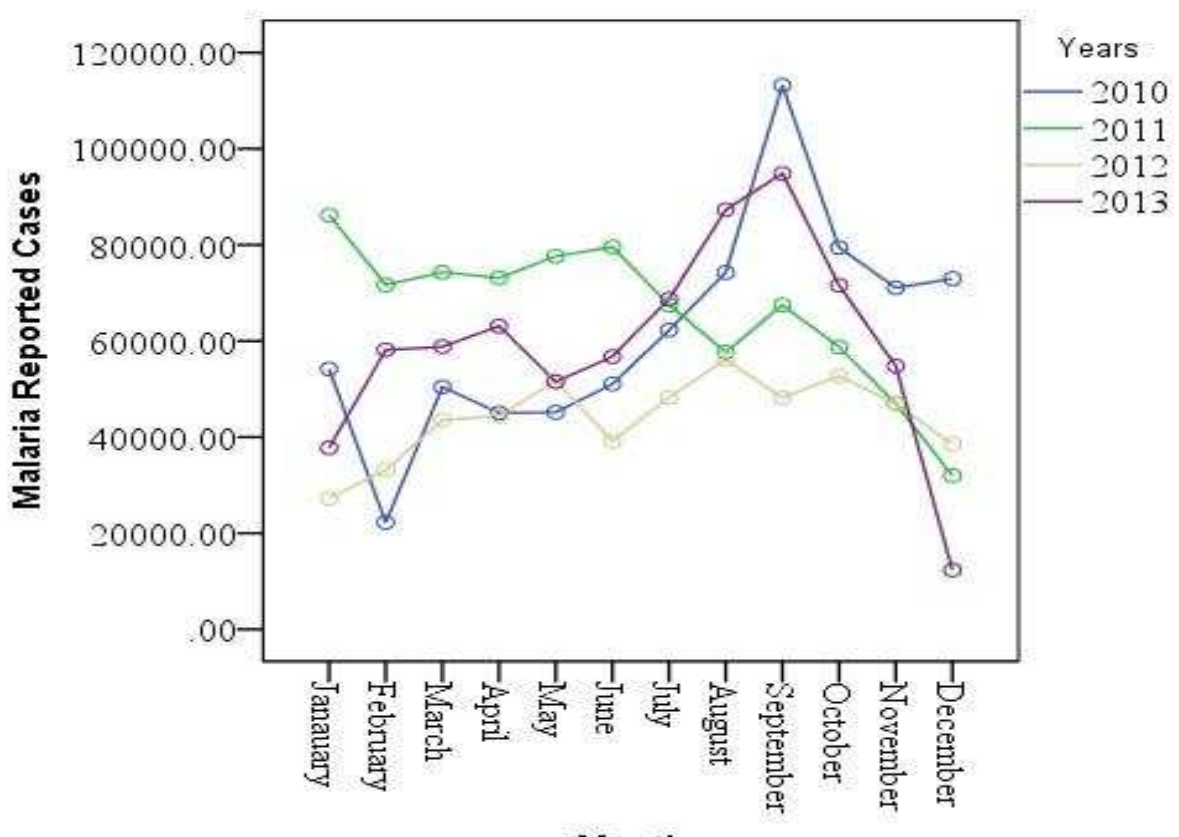

Months

Figure 2: Monthly reported malaria cases (2010-2013)

Annual Reported Malaria Incidence

A total of 3, 062, 812 of confirmed clinical malaria cases were reported throughout the period under study (2010 - 2013). The annual pattern of malaria cases also revealed a fluctuating trend. Figure 4 revealed a marginal increased in malaria cases from 2010 to 2011 . The cases sharply dropped from 2011 to 2012 and steeply increased again from 2012 to 2013. 


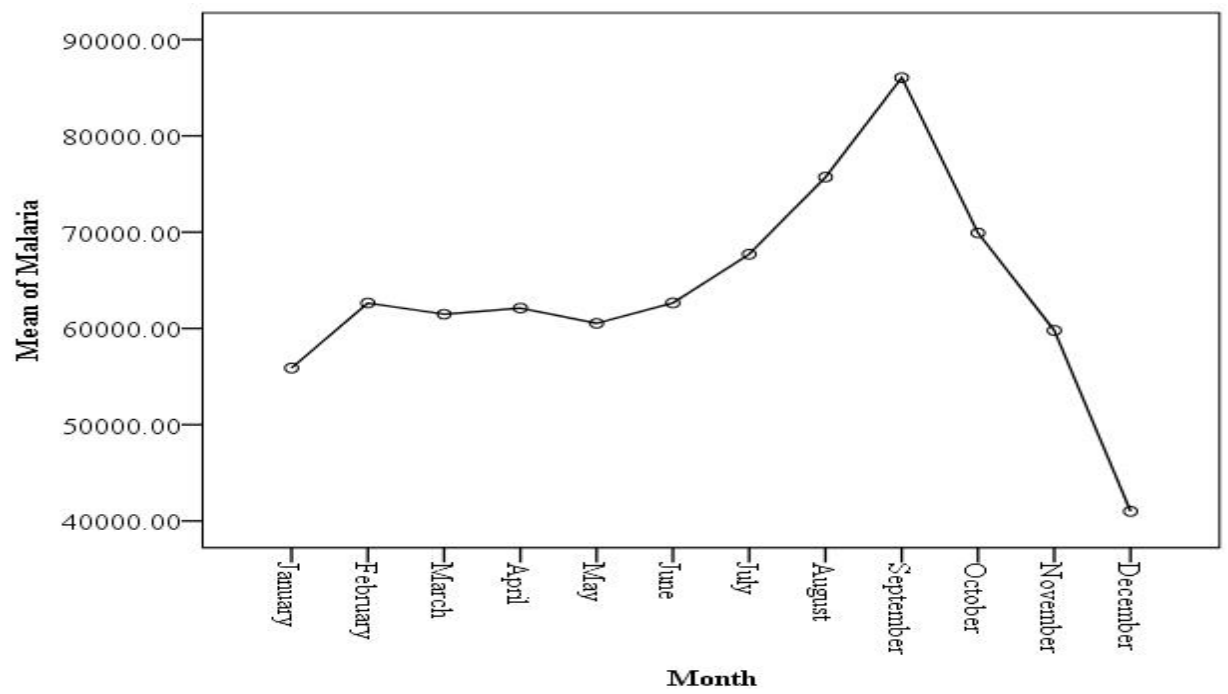

Figure 3: Mean monthly reported malaria cases

The distribution shows that the year 2012 recorded the lowest cases with 560,494 cases (or 18.3\%), while year 2011 has the largest number of records (858,061 cases representing $28.02 \%)$.

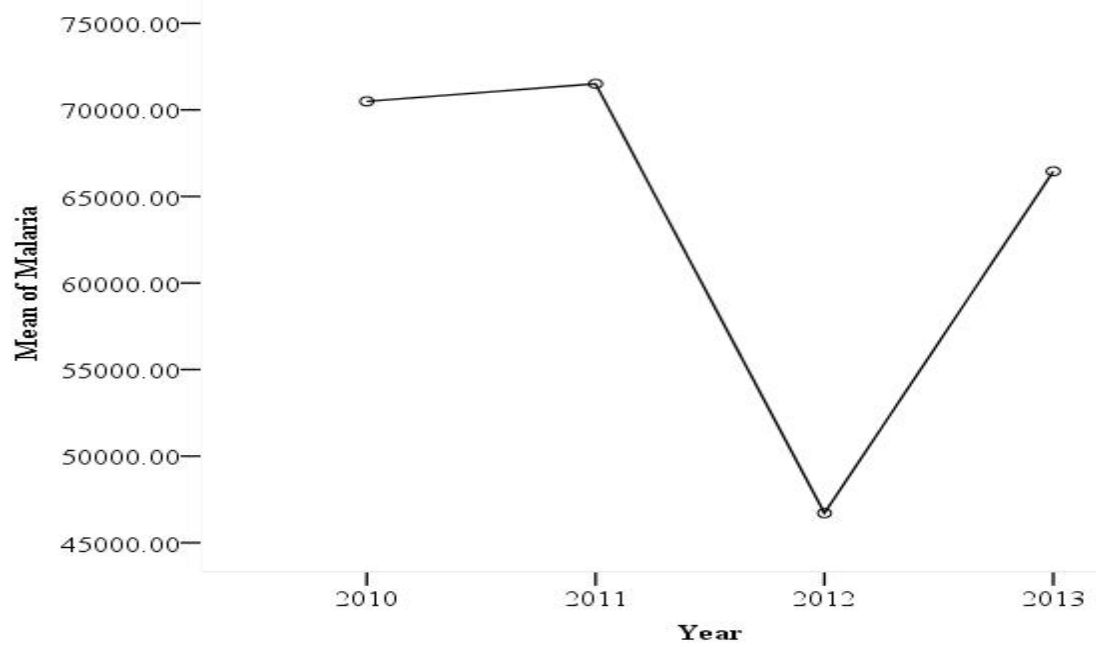

Figure 4: Annual reported malaria cases

\section{Forms of Malaria}

Two major forms of malaria based on severity were reported, they are uncomplicated and severe malaria. The study discovered high occurrence of uncomplicated than severe form of malaria. As regard to mean monthly cases, the months of August, September and October recorded more cases of uncomplicated form of malaria with mean cases records of 87308,80924 and 65625 in that order. February and December are the months associated with the lowest mean monthly uncomplicated cases of 33161 and 38958 respectively.

Severe form of malaria on the other hand, has its highest mean monthly incidence of 6906, 6015 and6027 recorded for April, June and July respectively. The lowest mean monthly severe cases of 2939 and 2045 were observed in the months of February and December. In the case of mean annual, uncomplicated malaria recorded its highest mean in 2011 and lowest in 2012. However, unlike uncomplicated malaria 2013 recorded the highest mean annual of severe malaria while 2012 registered the lowest mean annual just like uncomplicated form (Figure 5).

Mean Differences of Malaria Incidence using 3way Analysis of Variance (3-way ANOVA)

A three-way ANOVA between groups analysis was conducted to explore the mean differences between the dependent variable (malaria) and the fixed factors (months, years and forms). The following stated null hypotheses were tested:

$\mathrm{HO}_{1}$ : There is no significance difference of malaria cases between months of observation.

$\mathrm{HO}_{2}$ : There is no significance difference of malaria cases between the studied years.

$\mathrm{HO}_{3}$ : There is no significance difference between forms of malaria.

$\mathrm{HO}_{4}$ : There is no interaction effect between month, years and form of malaria. 


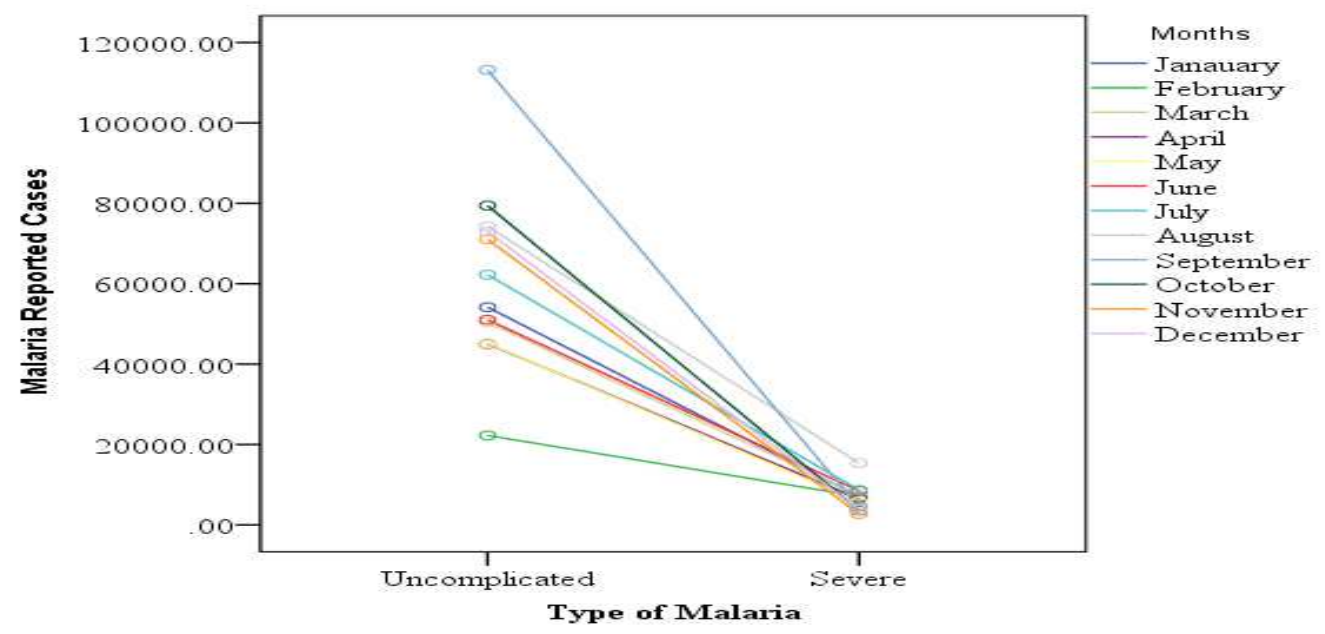

Figure 5: Reported malaria cases based on severity

Result (Table1) obtained using a factorial analysis of variance with three-between participant factors of months, years and forms of malaria revealed that there was a strong statistical significant main effect for monthly incidence of malaria $(F(11,96)=3.28, P=$ $0.001)$, there was a strong statistical significance main effect for the annual malaria cases $(F(3,96)=1.03 P=$ $0.001)$, there was a strong statistical significant main effect in the form of malaria $(F(1,96)=8.81, P=$ $0.001)$. Result further indicated a strong interaction effect between months, years and form of malaria ( $F$ $(80,96)=2.19, P=0.001)$.

242

Table 1: Test between subject effects of Malaria incidences using Univariate ANOVA

\begin{tabular}{lrrrrr}
\hline Source & \multicolumn{1}{c}{ Type III SS } & D F & \multicolumn{1}{c}{ Mean Square } & \multicolumn{1}{c}{ F } & $\boldsymbol{P}$ \\
\hline Corrected Model & $169149265499.250 \mathrm{a}$ & 95 & 1780518584 & $1.182 \mathrm{E}+30$ & 0.000 \\
Intercept & $1.92088 \mathrm{E}+11$ & 1 & $1.92088 \mathrm{E}+11$ & $1.275 \mathrm{E}+32$ & 0.000 \\
Months & 5427252727 & 11 & 493386611.6 & $3.276 \mathrm{E}+29$ & 0.000 \\
Years & 4661833445 & 3 & 1553944482 & $1.032 \mathrm{E}+30$ & 0.000 \\
Malaria Form & $1.32615 \mathrm{E}+11$ & 1 & $1.32615 \mathrm{E}+11$ & $8.805 \mathrm{E}+31$ & 0.000 \\
Months * Years * Malaria Form & 26445412327 & 80 & 330567654.1 & $2.195 \mathrm{E}+29$ & 0.000 \\
Error & $1.00 \mathrm{E}-13$ & 96 & $1.00 \mathrm{E}-13$ & & \\
Total & $3.61238 \mathrm{E}+11$ & 192 & & & \\
Corrected Total & $1.69149 \mathrm{E}+11$ & 191 & & & \\
\hline
\end{tabular}

\section{R Squared = 1.000 (Adjusted R Squared $=1.000)$}

To investigate these interactions further, Post hoc multiple comparison test on the groups using Bonferroni correction was performed. Results indicated that the mean differences between months throughout the observation period were statistically significantly different (table containing the result not included for its large size). Similarly, the mean differences between years under observation were statistically significantly different (Table 2).

Table 2: Bonferroni Multiple Comparison Test between Years for Malaria Incidence

\begin{tabular}{|c|c|c|c|c|c|c|}
\hline \multirow{3}{*}{$\begin{array}{l}(\mathrm{I}) \\
\text { Years }\end{array}$} & \multicolumn{2}{|l|}{ (J) } & \multirow{3}{*}{ S.E } & \multirow{3}{*}{ Sig. } & \multirow{2}{*}{\multicolumn{2}{|c|}{ 95\% Confidence Interval }} \\
\hline & Years & M D (I-J) & & & & \\
\hline & & & & & Lower Bound & Upper Bound \\
\hline \multirow[t]{3}{*}{2010} & 2011 & $-1535.2917^{*}$ & 0.000 & 0.000 & -1535.2917 & -1535.2917 \\
\hline & 2012 & $11015.2500 *$ & 0.000 & 0.000 & 11015.25 & 11015.25 \\
\hline & 2013 & $1035.4583^{*}$ & 0.000 & 0.000 & 1035.4583 & 1035.4583 \\
\hline \multirow[t]{3}{*}{2011} & 2010 & $1535.2917^{*}$ & 0.000 & 0.000 & 1535.2917 & 1535.2917 \\
\hline & 2012 & $12550.5417 *$ & 0.000 & 0.000 & 12550.5417 & 12550.5417 \\
\hline & 2013 & $2570.7500 *$ & 0.000 & 0.000 & 2570.75 & 2570.75 \\
\hline \multirow[t]{3}{*}{2012} & 2010 & $-11015.2500 *$ & 0.000 & 0.000 & -11015.25 & -11015.25 \\
\hline & 2011 & $-12550.5417 *$ & 0.000 & 0.000 & -12550.5417 & -12550.5417 \\
\hline & 2013 & $-9979.7917 *$ & 0.000 & 0.000 & -9979.7917 & -9979.7917 \\
\hline \multirow[t]{3}{*}{2013} & 2010 & $-1035.4583 *$ & 0.000 & 0.000 & -1035.4583 & -1035.4583 \\
\hline & 2011 & $-2570.7500 *$ & 0.000 & 0.000 & -2570.75 & -2570.75 \\
\hline & 2012 & 9979.7917* & 0.000 & 0.000 & 9979.7917 & 9979.7917 \\
\hline
\end{tabular}




\section{DISCUSSION}

This study describes the temporal patterns of malaria incidence. The findings show that malaria infections are observed in all the months of the period under study. This signifies that the disease remained endemic in the area. This could be attributed to the fact that Kano state has many irrigation structures (both small and large scales) established to promote food production and portable water supply in the state. Many other small dugouts reservoirs which supply domestic water to various rural communities especially in the periods were also available. Additionally, rivers, streams, open drainages, dumped garbage, ponds and wet lands were spread in the state. All these points might have provided suitable breading sites for mosquitoes during the dry season and often increased the population size of the mosquitoes. In addition poor urban planning system in the densely populated metropolis has favoured the vector by providing multiple breeding spaces. The housing types and environmental quality is poor in most neighbourhoods. Some houses are not only small but lack cross ventilation and this discourage the use of mosquito nets. This can explain the reason for high incidence of the disease even in the period of dry months. This finding was supported by several earlier works (Oesterholt et al., 2006; Gurmu, 2009; Lemessa, 2011; Coulibaly et al,. 2013; Kasasa, 2013 and Kumar et al., 2014).

For long Kano remained the most influential commercial centre in the Sudan region and had trade links with Mediterranean in the north and even Yoruba states to the south (Falola, 2002). This position of the state allows for large scale movement of people into and outside the state, and could be considered as among the factors for persistence incidence of malaria in the area. This observation could be supported by the work of Prothero (1977) who relate population movement with malaria.

According to him movement can exposed people to malaria risks, as they move between and through different ecological zones. Again, exposure of people with little or no immunity to infected persons, particularly when strains of malaria are drugs resistance can accelerate the rate of transmission. Still, movement exposes people to physical and psychological stresses and consequently increases their susceptibility to malaria and other infections (Prothero, 1994).

Though malaria episodes are recorded all the year round, most of the cases concentrated between May and October when the area experiencing its rainy period with September being the peak month. But there are inter-annual variation which may be related to variations in climate and other environmental risk factors. This finding deviated from that of Laah et al. (2008) who found June and July as the peak months of malaria cases in Gwagwalada Abuja. This could be due to the fact that, Abuja start having its rainfall earlier than Kano thereby giving an opportunity for the mosquito to established its way earlier than Kano. The study also discovered that during the period under observation (2010-2013) nearly $54 \%$ of all reported malaria cases occurred in the wettest months. This result is very close to that of Abeku et al. (2003) who found $55 \%$ of the malaria cases in part of Ethiopia occurred in rainy season. However, the result is lower than that of Xion et al. (2010) who discovered nearly $70 \%$ of annual malaria cases being reported between May and October in Hainan China.

An annual fluctuation was observed for the studied period in this study. High incidence occurs in 2011 and low incidence in 2012. The drop of the disease incidence is likely to be influenced by intervention measures adopted, such as mass distribution of insecticide treated nets (ITNs), increased availability of the new effective drug (ACT) for treating malaria, indoor residual spraying and regular larviciding activities in the area. In addition, low incidence in the year 2012 coincides with the period of heavy rainfall which caused flood in many parts of the state. Too much rainfall according to many writers (Gubler et al., 2001; McMichael and Martens, 1995 as cited by Devi and Jauhari, 2006, and Haque et al., 2010) destroys breeding sites and flush away mosquito larvae hence reduced its population size and subsequent transmission of the disease.

The study further discovered that vast majority of malaria cases $(90.7 \%)$ are uncomplicated ones while severe malaria account for only $9.3 \%$ of the reported cases. The percentage of severe malaria in Kano State is higher than $1-2 \%$ reported by Greenwood et al. (1991) in Africa. This might be related to the scale of the study and perhaps it is showing that in some clusters in Africa it could be higher. It could also be that uncomplicated malaria can progress to severe disease within few hours particularly where early and effective treatment was not started quickly. The fact that in Africa and Kano state in particular, there are delays in reporting illness to the health facility and or in receiving the appropriate treatment. This could be attributed to the prevailing attitude of self-medication practice and poor health care delivery.

\section{CONCLUSION}

This study revealed that malarial infection is a common illness occurring all the year round thereby exposing many people to the risk of infection. Result further shows high density of cases in wet season than in dry season. The study therefore provides valuable information regarding the temporal pattern of malaria.

\section{Recommendations}

This study recommends that intensive effort should be exerted toward controlling the disease attack by educating people on the danger of the disease and how to prevent its potential risk. The use of insecticide treated nets, indoor spraying, larviciding practice and other vector controlling activities should be intensified. In addition, government at all levels should ensure that incidence records of the disease are properly documented, so as to periodically trace the pattern of the disease.

\section{Authors' contributions}

All authors contributed in the conceptualization and design of the study. IIY carried out data cleaning, analysis and drafting of manuscripts. All authors provide substantial input, read and approved the final draft.

\section{Conflict of interest}

The authors have no conflict of interest 


\section{REFERENCES}

Abeku, T.A, van Oortmarsen G.J, Borsboom G, de Vlas S.J, Habbema, J.D.F: Spatial and Temporal variation of malaria epidemic risk in Ethiopia: Factors involved and implications. Acta Trop 2003, 87: 331-340

Ayanlade, A., Adeoye, N.O and Babatimehin, O: Intraannual climate variability and malaria transmission in Nigeria. Bulletin of Geography. Socio-economic series no. 21(2013): 7-19

Coulibaly, D. Rebandet, S., Travassos, M.,Tolo, Y.,Laurens, M., Kone, A.K., Traore, K., Guindo, A., Diarra, I., Niagaly, A., Daou, M., Dembele, A., Sissoko, M., Kouriba, B., Dessay, N., Gaudart, J., Piarroux, R., Thera, M.A., Plowe, C.V. and Doumbo, O: Spatio-temporal analysis of malaria within a transmission season in Bandiagara, Mali. Malaria Journa/2013 12: 82

Devi, P. and Jauhari, K: Climatic variables and malaria incidence in Dehradun uttarnchal, India. Journal of Vector Borne Diseases 2006 43:21-28

Falola, JA. (2002) "Kano" in Africa Atlases- Atlas of Nigeria Les Editions J. A Paris- Frence.

Federal Republic of Nigeria Official Gazette, 2007 No.24 Vol. 94

Federal Ministry of Health: Federal Republic of Nigeria training manual for management of malaria in Nigeria participant manual, Federal Ministry of Health National malaria and vector control division Abuja - Nigeria, 2009

Greenwood, B., Marsh, K. and Snow, R.W: Why do some African children develop severe malaria? Parasitol Today, 1991 7: 277-281

Gubler, DJ. Reiter, P. Ebi, KL. Yap, W. Nasci, R. Patz, JA. :Climatevariability and change in the United States: Potential impacts on vector-and rodent borne diseases. Environ Health Perspect 2001, 109 (Suppl 2): 223-233

Gurmu, A.D.(2009) Vulnerability Analysis and malaria risk mapping in Awassa and Wondogenet Wodas. An M Sc thesis submitted to the School of Graduate Studies. Addis Ababa University, Ethiopia.

Haque U. Hashizumen, M. Glass, GE. Dewan, AM. Overgaard, HJ. Yamaota, T. :The role of climate variability in the spread of malaria in Bangladeshi highlands. PLoS One, 2010, 5:e14341

Kasasa, S., Asoala, V., Gosoniu, L., Anto, F., Adjuik, M., Tindana, C., Smith, T., Owuso-Agyei, S. And Vounatsou, P: Spatio-temporal malaria transmission patterns in Navrongo demographic surveillance site, northern Ghana. Malaria Journal 2013, 12:63

Katsayal, U.A, and Obamiro, K.O. (2007) In-vivo Antiplasmodial activity and phytochemical screening of ethanolic extract of the leaves of Cissampelos Mucronata. Nigerian Journal of Pharmaceutical Sciences Vol. 6 No. 2 pp 111115

Kumar, D.S., Andimuthu, R., Rajan, R. And Venkatesan, M.S: Spatial trend, environmental and socioeconomic factors associated with malaria prevalence in Chennai. Malaria Journal 2014 13:14

Laah, J.G., M. Zubairu and O.O. Ifatimehin 'Trend and Seasonal Variation in Malaria Caseloads in Gwagwalada, Nigeria. The Zaria Geographer (2008), Vol. 17, No. 1 pp. 108-117

Lamikanra, O.T: A Study of malaria parasitaemia in pregnant women, placenta, cordblood and newborn babies in Lagos, Nigeria. West Afr J Med 1993; 12:213-217

Lemessa, A. (2011) GIS and Remote Sensing Based malaria risk mapping in Fentele Woreda, East Shao zone, Ethiopia. An M Sc thesis submitted to the School of Graduate Studies Addis Ababa University, Ethiopia

McMichael, A.G and Martens, W.J.M (1995) The health impacts of global climate: Grappling with scenarios, predictive models and multiple uncertainties. Ecosystem Health, 1(1), 23-33

Mustapha, A., Yakudima, I.I., Alhaji, M., Nabegu, A.B., Dakata, F.G.D., Umar, Y.A. and Musa, B.U (2014) Overview of the physical and human setting of Kano region, Nigeria. Research Journali's Journal of Geography vol.1 No.5

Oesterholt, M., Bousema, J.T., Mwerinde, O.K., Harris, C., Lushino, P., Masokoto, A., Mwerinde, H., Mosha, F.W. and Dreseley, C.J: Spatial and temporal variation in malaria transmissionin a low endemicity area in northern Tanzania. Malaria Journal 2006 5:98

Olofin, E.A. (1987) Some aspect of physical Geography of Kano Region and related human responses. Department of Geography, Bayero University, Kano (BUK), Debis Standard Printers, Kano

Olofin, E.A. (2008). The Physical Setting. In Olofin, E.O., Nabegu, A.B., Dambazau, A.M. (eds). Wudil within Kano region: a geographical synthesis. Adamu Joji Publishers Kano City

Prothero R.M. "Disease and Mobility: a neglected factor in epidemiology" International Journal of Epidemiology 6:259-267 (1977).

Prothero R.M. "Force movements of population and health hazards in tropical Africa" International journal of Epidemiology 23: 657-664 (1994)

Roll Back Malaria progress and impact series- Focus on Nigeria (2012)

World Malaria Report (2014) http://www.who.int/malaria/world malaria rep ort 2014/en/index.html

WHO (2002): Roll Back Malaria Fact Sheet 2. www.rbm.who.int.

World Health Organisation (2011) Expert Committee on Malaria: World malaria report. Geneva: WHO

Xiao, D., Long, Y., Wang, S., Fang, L., Xu, D., Wang, G., Li, Lang., Cao, W. And Yan, Y: Spatiotemporal distribution of malaria and the association between its epidemic and climate factors in Hainan, China. Malaria Journa/2010, 9: 185

Yahya, A., Tyav, Y.B. and Nura, M.S. (2014) Seroprevalence of paediatric malaria infections in two hospitals in Kano State, Nigeria. International Journal of Sciences: Basic and Applied Research (IJSBAR) (2014) Vol 14, No.1 pp 252-264 